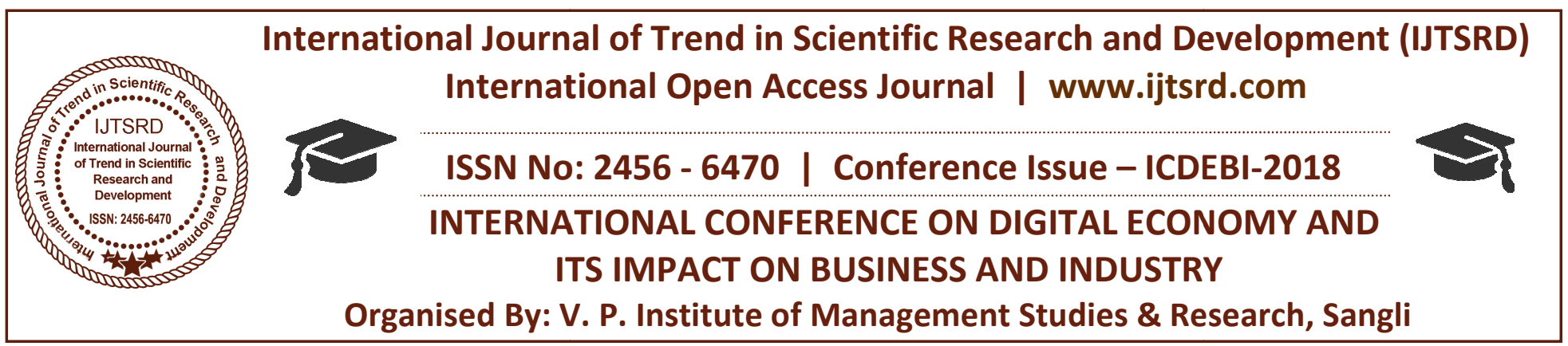

\title{
Knowledge Management in Educational Institutes with the Help of Digitalization
}

\author{
Nishat. Z. Haveri \\ Assistant Professor, College of Non-Conventional Vocational Courses for Women, \\ Kolhapur, Maharashtra, India
}

\section{ABSTRACT}

Knowledge can be termed as an output of information analysis. It is further classified as explicit and tacit knowledge. The amount of knowledge generated in Educational Institutes is considerably huge. Every Educational Institute (EI) has teachers who work on a specific subject and its related domains for years all together. These teachers can be termed as experts in their subjects. Subject experts spend a lot of time and efforts to generate knowledge for improving teaching process. By applying their analytical and cognitive skills and experience they generate a set of knowledge that is unique and precious in nature.

When these experts leave the organization, their expertise and the knowledge they generate is also lost. There should be efforts taken to extract this knowledge from the experts and preserve it. Many organizations use the concept of Knowledge Management (KM) for preserving the knowledge generated within organization.

This paper is an attempt to draw a conceptual framework for use of KM techniques in Educational Institutes. It tries to explore the possibility and challenges involved in using KM concepts to preserve knowledge with more stress on tacit knowledge. Further it attempts to examine the role of digitalization in the above mentioned process.

KEYWORD: Knowledge Management, Digitalization, Educational Institutes.

\section{INTRODUCTION}

Data is a collection of facts and figures. When data is processed for a specific purpose it gets converted into information. Information thus produced is either stored or used as and when required. When people intend to use information, they interpret it according to their own level of understanding. Along with this they use their experience, previously stored information, cognitive skills and expertise. This process leads to knowledge generation. Thus, it can be said that knowledge is highly dependent on the person that creates it. Every organization creates knowledge related to its domain. Knowledge is a valuable resource and it is necessary that organizations store the generated knowledge for future use. Knowledge Management (KM) concepts are widely used in organizations for this purpose. According to Luan \&Serbian (2002), "KM is about using the brain power of an organization in a systematic and organized manner in order to achieve efficiencies, ensure competitive advantage and spur innovation". Educational Institutes create knowledge on a regular basis .It is necessary that Educational Institutes store, preserve and reuse the knowledge they generate. Use of KM concepts in Educational Institutes can help achieve this objective. The concept of $\mathrm{KM}$ is gaining popularity in Educational Institutes. The purpose of this paper is to study the application of KM concepts in Educational Institutes and the specific challenges associated with capturing and sharing of knowledge, with specific emphasis on tacit knowledge. It also attempts to highlight the use of digitalization to strengthen the process of knowledge sharing. 


\section{Why KM is necessary for Educational Institutes}

It is important to understand the nature of working of Educational Institutes with respect to knowledge. It can be rightly said that Educational Institutes are one of the most important knowledge generation centres in the society. Teachers in Educational Institutes work on their domain subject for a number of years. They are involved in learning, researching and teaching certain subjects for a long duration. They gain rich experience and new insights in these subjects. Thus they are capable of handling subject specific problems more effectively as compared to new entrants in the same field. They not only gather information and knowledge and store in their brain, but also are capable of using it as and when necessary. They know which piece of information is to be used in which situation. So, we can say that they have subject knowledge along with the knowledge of when and how to use the subject knowledge. They continuously generate knowledge for teaching or research purpose. These teachers become experts of their subjects. According to Awad \&Ghaziri (2007) Knowledge is an attribute of expertise. They further explain Knowledge as "human understanding of a specialized field of interest that has been acquired through study and experience." Therefore the subject experts in Educational Institutes are a rich source of subject specific knowledge.

Knowledge can be explicit or tacit (Nonaka\& Takeuchi, 1995). Explicit knowledge is the one which can be easily transferred from one person to another. Subject experts can share explicit knowledge by documenting it in form of text, books, articles, research papers etc. or can be communicated to intended user relatively easily. Tacit knowledge is generated when people use their cognitive skills, experience and concepts in their head to analyse information. This is what the subject experts in Educational Institutes do. Apart from the learned concepts and the documented knowledge, subject experts use their experience, thinking abilities, analytical skills, heuristics and cognitive skills to generate knowledge. We call this as tacit knowledge. Educational Institutes generate explicit and tacit knowledge in large amounts. With the continuously changing educational environment and constant challenges it is necessary that Educational Institutes store the generated knowledge. Many Educational Institutes and Universities are using KM systems wholly or partially for this purpose.
According to Sharma, M \&Kaur, M. (2016) KM in educational institutions involves the creation, empowerment, maintenance and safety of the knowledge. They further emphasis that the effective application of the KM strategy and practices in the Educational Institutes can result significant improvement in the functioning and operations of the institutions. As mentioned in the earlier part of paper, it is easier to manage explicit knowledge. It can be documented and stored in any form desired by the Educational Institutes. The major problem is with managing tacit knowledge. According to Dhamdhere, S. N (2015), "tacit knowledge is personal, context specific, therefore hard to formalize and communicate."Because of its unique nature it becomes difficult to capture and share tacit knowledge completely.

\section{Capturing and Sharing of Explicit and Tacit knowledge in Educational Institutes}

According to Hong, Suh\&Yoo(2011), “ Knowledge sharing is the process by which knowledge held by an individual is converted into a form that can be understood, absorbed and used by other individuals through channels or networks between known providers and seekers". Nonaka and Takeuchi (1994) introduced SECI model. It suggests of four steps for knowledge sharing, as follows:

i. Socialization- conversion of with tacit to tacit.

ii. Externalization-conversion of tacit to explicit

iii. Combination- conversion of explicit to explicit.

iv. Internalization-conversion of explicit to tacit.

The model is extensively used in many fields including education. Explicit knowledge is comparatively easier to capture and share. As it can be documented, it's easier to share and preserve it. The extent to which tacit knowledge is shared in Educational Institutes is limited. As noted earlier, tacit knowledge is subjective and highly dependent on the person who possesses it. Hislop (2009) states that "Knowledge is always stored in people's brains, sharing of tacit knowledge is difficult, time consuming and one of the biggest challenges of KM.'The best example to explain this is teaching someone to play a musical instrument. A Person can be taught all the technical details of how to play an instrument. But using that instrument to create new tunes or melodies depends on that persons own abilities. 
Yu \& Zhou (2015) have listed four types of tacit knowledge sharing processes as:

i. Peer review - It is a standard processes, where teachers get there articles, books etc. reviewed. They also get suggestions and advice from the reviewers.

ii. Learning community - It acts as a platform to share ideas, concepts and experience.

iii. Thumb - a - lift - It includes making use of online forums and discussion platforms to share tacit knowledge.

iv. Academic conferences- Where ideas, research etc. can be shared

Apart from above stated processes teachers and subject experts can share tacit knowledge by frequent communication new teachers should be continuously guided and trained by the subject experts, this can save a lot of organization time. New teachers should be given a set of best practices for teaching a certain subject, to avoid the situation of 'Reinventing the wheel'. There should be face- to- face interactions with the subject experts. A lot of tacit knowledge can be captured by direct observation; therefore teachers should attend lectures of subject experts and observe them in action. Educational Institutes can help the new teachers to grow by providing them mentors who are experts of their domain subject. This direct interaction facilitates sharing of tacit knowledge. When the subject experts are leaving the Educational Institutes the organization fears loss of valuable tacit knowledge. Practically these experts cannot be stopped from leaving. Educational Institutes can try and extract tacit knowledge with them by various methods like interviews, audio-video recordings, suggestions and best practices. Here the concept of digitalization can play a pivotal role, which will be discussed in latter part of the paper.

\section{Problems in process of Sharing Tacit Knowledge}

1. It is subjective - because of the fact that it is highly depend on source person. Even though it is transfer it may not be completely expectable by others

2. Personal Bias, experience plays a very important role in tacit knowledge creation. To make others understand this is very difficult.

3. Willingness to share knowledge is very crucial. If subject experts lack this willingness they will not share it completely.
4. Feeling of being superior to others is also a hindrance in knowledge sharing.

5. In many cases teachers may not be aware of the value of tacit knowledge they carry with themselves.

6. Inhibition and lack of interest can also be a major hindrance.

\section{Use of Digitalization for capturing and sharing of knowledge}

Oxford dictionary defines digitalization as

"Digitalization is the way in which many domains of social life are restructured around digital communication and media infrastructure".

The concept of digitalization is gaining moment rapidly throughout the world. According to doctor Subramacharya, P. (2017) "Digital economy is regarded as the third industrial revolution throughout the world". Indian Government has also launched many programs for digitalization of the economy. Monisha, Budhiraja, K \&Kaur, J. (2017) describe digitalization as use of "Electronic technology in various fields that make the collection, storage and processing of data and information easier and convenient to a large extent and this also facilitates the end user to access the needed data throughout the world by simply using the established protocols". Digitalization is used in education sector also. One of its important uses is in capturing and sharing knowledge. As explain earlier it is the process of using technology for capturing, storing and then reusing data and information. Machekhina (2017) notes that digitalization of education is a powerful trend in terms of reformation and modernization of global education environment. These technologies can be used very aptly for capturing knowledge especially in case of tacit knowledge. Audio and video recordings of classroom sections of subject experts can be used to capture tacit knowledge. Similarly, all the tacit and explicit knowledge in the organization can be used to create knowledge repository. This knowledge repository can be modelled on the concept of Experts Systems. Educational Institutes can go on adding the captured knowledge and make it available to other subject teachers and new teachers this knowledge repository can be used in training and development of teachers it makes sure that the knowledge stays in the organization even if the subject experts live the organization. 


\section{Conclusion:}

Educational Institutes are at the centre of Knowledge creation and sharing. Owing to the dynamic nature of knowledge, its retention is becoming a challenge for the institutes.KM activities along with the digitalization technologies can help education sector in improving the quality of teaching-learning process, research activities. It can help in imbibing quality throughout the organizational processes. Educational Institutes applying KM concepts will have the much needed competitive edge over the others.

\section{REFERENCES:}

1. Awad, E. M. and Ghaziri, H.(2007). Knowledge Management, Delhi: Pearson Education.

2. Dhamdhere, S. N. (2015).Knowledge Management Applications and status in Indian education system: a survey, Elixir International Journal (ISSN 2229 712X), pp 30815-30823. Web: www.elixirpublishers.com

3. Hislop, D. (2009). Knowledge Management in Organizations: A critical Introduction, 2nd Edition, Oxford University Press, New York.

4. Hong, D. Suh, E. and Koo, C.(2011).Developing Strategies for Overcoming barriers to knowledge sharing Based on Conversational Knowledge Management: A Case Study of A Financial Company, Expert Systems of Applications 38(12): pp14417-14427.

Web: http://dx.doi.org/10.1016/jeswa.2011.04.072

5. Luan, J. and Serban, A. M.(2002). Overview of Knowledge Management. New direction for institutional research, Quarterly review of economic and finance, 113, pp 605-631.

6. Machekina, O. (2017). Digitalization of education as a trend of its modernization and reforming. Revista Espacios(ISSN 0798 1015).

7. Monisha, Budhiraja, K. and Kaur, J. (2017). Digitalization in Indian Economy, BMIETJournal of Science, technology and Management, Vol 1(1), pp 1-11.

8. Nonaka, I. and Takeuchi, H. (1994). A Dynamic Theory of Organizational Knowledge Creation. Organization Science, Vol-5(1) pp 14-37

9. Nonaka, I. and Takeuchi, H. (1995). The Knowledge -Creating Company: How Japanese Companies Create the Dynamics of Innovation, Oxford University Press, New York, NY.

10. Sharma,M. and Kaur, M.(2016). Knowledge Management in Higher Institutions. IRAInternational Journal of Management \& Social Sciences (ISSN 2455-2267), 4(3), pp548-555.

11. Subramacharya, P. (2017). Digitalization in India: A needed Gadget for Business Environment. IRAInternational Journal of Management \& Social Sciences (ISSN 2455-2267), 6(2),pp 253-259.

12. Yu, D. and Zhou, D. (2015). Tacit Knowledge Sharing Modes of University Teachers from the Perspectives of Psychological Risk and Value, International Journal of Higher Education,4(2) ,pp 214-224. 